IZA DP No. 6092

The Effects of Children's ADHD on Parents'

Relationship Dissolution and Labor Supply

Anette Primdal Kvist

Helena Skyt Nielsen

Marianne Simonsen

October 2011 


\title{
The Effects of Children's ADHD on Parents' Relationship Dissolution and Labor Supply
}

\author{
Anette Primdal Kvist \\ Aarhus University \\ Helena Skyt Nielsen \\ Aarhus University \\ and IZA \\ Marianne Simonsen \\ Aarhus University \\ and IZA
}

Discussion Paper No. 6092

October 2011

\author{
IZA \\ P.O. Box 7240 \\ 53072 Bonn \\ Germany \\ Phone: +49-228-3894-0 \\ Fax: +49-228-3894-180 \\ E-mail: iza@iza.org
}

\begin{abstract}
Any opinions expressed here are those of the author(s) and not those of IZA. Research published in this series may include views on policy, but the institute itself takes no institutional policy positions.

The Institute for the Study of Labor (IZA) in Bonn is a local and virtual international research center and a place of communication between science, politics and business. IZA is an independent nonprofit organization supported by Deutsche Post Foundation. The center is associated with the University of Bonn and offers a stimulating research environment through its international network, workshops and conferences, data service, project support, research visits and doctoral program. IZA engages in (i) original and internationally competitive research in all fields of labor economics, (ii) development of policy concepts, and (iii) dissemination of research results and concepts to the interested public.
\end{abstract}

IZA Discussion Papers often represent preliminary work and are circulated to encourage discussion. Citation of such a paper should account for its provisional character. A revised version may be available directly from the author. 
IZA Discussion Paper No. 6092

October 2011

\section{ABSTRACT \\ The Effects of Children's ADHD on Parents' Relationship Dissolution and Labor Supply*}

This paper uses Danish register-based data for the population of children born in 1990-1997 to investigate the effects on parents of having a child with attention-deficit/hyperactivitydisorder (ADHD). Ten years after birth, parents of children diagnosed with ADHD have a 75\% higher probability of having dissolved their relationship and a 7-13\% lower labor supply. Exploiting detailed information about documented risk factors behind ADHD, we find that roughly half of this gap is due to selection. However, a statistically and economically significant gap is left, which is likely related to the impact of high psychic costs of coping with a child with ADHD.

JEL Classification: $\quad I 12, \mathrm{~J} 12, \mathrm{~J} 13, \mathrm{~J} 22$

Keywords: $\quad$ ADHD, child health, marital dissolution, labor supply

Corresponding author:

Helena Skyt Nielsen

Department of Economics and Business

Aarhus University

Bartholins Allé 10

8000 Aarhus C

Denmark

E-mail: HNielsen@econ.au.dk

\footnotetext{
* We thank the Danish Psychiatric Central Register for access to data. Financial support from the Danish Council for Independent Research (Sapere Aude Starting Grant, 10-079597) is gratefully acknowledged.
} 


\section{INTRODUCTION}

Attention-Deficit/Hyperactivitiy-Disorder (henceforth ADHD) is the most common mental health disorder among young children. Approximately 3-5\% of children suffer from the disorder, which is characterized by attention deficiencies, hyperactivity, and impulsiveness but often children with ADHD also suffer from comorbidities and learning problems (Child and Youth Psychiatric Society, 2008). A scarce literature indicates that as a consequence of this, ADHD has an enormous impact on the child's life in terms of accumulation of human capital (Currie and Stabile, 2006), peer relationships, and low selfesteem (Wehmeier et al., 2010). Moreover, the disorder seems to influence siblings (Currie and Stabile, 2006; Fletcher and Wolfe, 2008) and classmates (Aizer, 2009) negatively. What has only received little attention so far is to what extent the disorder affects the outcomes of parents. In this paper, we analyze whether having a child with ADHD affects relationship dissolution and labour supply in a ten year period after child birth.

There are many reasons why children with ADHD may affect parental outcomes. The arrival of a disabled child can be seen as an unanticipated shock to the relationship. This incidence may lead to conflicts that challenge the parents' relationship thereby imposing higher psychic costs on the parents than in families without a child affected by ADHD (Wehmeier et al., 2010). But having a child with ADHD may also affect the parents' relationship positively by bringing the family closer together (Reichman et al., 2008). Moreover, the prospects of caring for a disabled child alone may affect a parent's decision about dissolving the relationship. Therefore, the total impact on the risk of dissolution may be either negative or positive. If having a child with ADHD promotes family dissolution, the child who already faces obstacles due to the disorder is also more likely to experience negative consequences from a parental disruption in terms of emotional distress and worse educational outcomes (Kravdal et al., 2009; Francesconi et al., 2010; Björklund et al., 2007).

A child with ADHD may also affect the parents' time allocation by requiring enhanced time investment due to more need for guidance in daily activities compared to a child without ADHD (Green et al., 2005). To cope with the increased care-giving burden and the higher time-demand both parents may cut back on working hours. Or, they may rely on a household specialization strategy where one parent, most likely the mother, reduces the time spent on the labor market to engage more in child-caring activities and the father specializes in market work. In some cases, the mother may even withdraw from the labor market to devote all her time to child-caring and other home-oriented activities. These higher investments in the non- 
market sector are marriage-related activities, which reduce the risk of marital dissolution (Becker et al. 1977).

Despite the fact that ADHD is a widespread and important phenomenon, there are only few papers specifically investigating the link between ADHD in children and parent's outcomes in general. In fact, the only paper we are aware of is Wymbs et al. (2008) who report a higher divorce rate for parents of children with ADHD. A related paper by Hartley et al. (2010) finds a higher divorce rate for couples with children and adolescents with Autism Spectrum Disorders (ASD).

Apart from providing information about effects of ADHD in itself, our paper also contributes to a larger literature on the relationship between child health more broadly and parents' outcomes. Most existing studies of health and relationship status focus on infant health or low birth weight (e.g. Fertig, 2009; Reichman et al., 2004) or broader health measures describing delayed growth or development and physical ailments occurring early in life (Corman and Kaestner, 1992). All these studies find that poor health of the child is statistically and positively associated with relationship dissolution. The existing work on the relationship between child health and parents' labor supply focuses on the labor market behavior of the mother. ${ }^{1}$ Most papers find that the presence of a disabled or ill child affects the mother's number of working hours and/or employment status negatively (e.g. Corman $e t$ al., 2005; Gould, 2004; and Powers, 2003), while Zimmer (2007) finds that the effect disappears when applying an instrumental variable for (self-assessed) access to care.

In the existing studies, the available set of control variables is often very limited and only includes standard socio economic and demographic variables (e.g. age, parental education, and year of birth). In some cases retrospective self-reported birth complications (Mauldon, 1992) or prenatal maternal behavior is controlled for (Reichman et al., 2004). Since we expect families with disabled children to be disadvantaged in many respects, access to only very limited background information may in part explain the large estimated effects: Reichman et al. (2004), for example, find that the probability of dissolution is 10 percentage points higher 12-18 months after birth if the child is in poor health and Corman et al. (2005) find an employment reduction due to poor child health of 8 percentage points at the extensive margin and 3 hours per week at the intensive margin.

In this paper we examine how the presence of a child with ADHD affects the risk of relationship dissolution (civil status analysis) and both parents' labor supply (labor supply

\footnotetext{
${ }^{1}$ One exception is Noonan et al. (2005), who considers labor supply of fathers.
} 
analysis) during each of the ten years after the birth of the child. We focus on an ADHD disorder of the firstborn child in the family.

In the civil status analysis, the focus is on the impact on relationships and not only marriages since an increasing number of couples choose to have children without being married. In the labor supply analysis, we examine both the intensive and extensive labor supply.

We exploit detailed register-based information about ADHD diagnoses and the main risk factors behind ADHD. We find that parents of a child suffering from ADHD have a $75 \%$ higher probability of having dissolved their relationship and a 7-13\% lower labor supply after ten years. However, half of this gap is due to selection. After accounting for this, we find that having a child with ADHD increases the probability of non-cohabitation after ten years by 13 percentage points, while employment is reduced by about 7 and 5 days each year at the end of the ten-year period for the mother and the father, respectively. The labor supply effect for fathers tends to be driven by boy children. In our sensitivity analysis, we find that the overall result of a detrimental effect of having a firstborn child diagnosed with ADHD on parental outcomes is not explained by the presence of younger siblings and having a second or a later child with ADHD

\section{BACKGROUND INFORMATION ABOUT ADHD}

This section summarizes key information about ADHD that is important for establishing a credible identification strategy and subsequently for interpreting results. We describe the prevalence of the disorder and discuss potential causes of ADHD and core symptoms associated with ADHD. Finally, we present possible treatment strategies and discuss how these may interact with the quality of parents' relationship and their labor supply decisions.

\section{Prevalence of ADHD}

ADHD prevails in 3-5\% of children. The disorder occurs more often among boys than girls with a gender ratio ranging from 6:1 to 9:1 in clinical populations (Gaub and Carlson, 1997). However, the gender ratio for children in population-based studies is typically lower 
(approximately 3:1) which suggests under-recognition of girls with ADHD in clinical populations. $^{2}$

Table 1 summarizes the prevalence of ADHD in our sample of firstborn children (further details about our data and the specific sample follow later). We find that $1.4 \%$ of the children are diagnosed with ADHD, which is lower than the 3-5\% which is based on the American diagnosis scheme DSM-IV. ${ }^{3}$ This could occur for two reasons: Firstly, Danish children are diagnosed according to the classification scheme ICD-10, which uses the diagnosis category hyperkinetic disorder. The latter category represents a subgroup of ADHD used in DSM-IV and the prevalence is therefore lower. According to the Child and Youth Psychiatric Society (2008) 1-2\% is diagnosed with a hyperkinetic disorder. Secondly, for the purpose of this study, we only observe children diagnosed at general hospitals. Therefore, if the number of cases diagnosed at private clinics is large, our control group will be contaminated and our estimates will be biased towards zero. If we assume that children who are treated with ADHD medication without being diagnosed at general hospitals, have instead been diagnosed at private clinics and conservatively assume that private physicians have the same propensity to treat as physicians employed at general hospitals, then the extent of unobserved diagnoses is about $33 \%$, see Dalsgaard, Nielsen and Simonsen (2011). ${ }^{4}$ If we instead (in line with anecdotal evidence from the press and from discussions with child psychiatrists) assume that private physicians treat more intensively, the extent of unobserved diagnoses will be lower. Under the extreme assumption that private clinics treat all diagnosed cases, the extent of unobserved diagnosed will instead be $10 \%$. As a robustness check, we add children without an observed diagnosis who are in pharmacological treatment with ADHD medication to our definition of children with ADHD, and furthermore, we study Northern Jutland separately because we expect potential problems with unregistered diagnoses to be larger in Northern Jutland, where the capacity of the general hospital is most limited.

\footnotetext{
${ }^{2}$ This may be because symptoms of ADHD in boys are more recognisable than in girls. Girls suffering from ADHD often have lower ratings on hyperactivity, impulsivity, and inattention than boys. Furthermore, girls have fewer externalising and more internalizing comorbid conditions than boys, see Gershon (2002).

3 This prevalence is supported in studies from different countries, see Child and Youth Psychiatric Society (2008).

${ }^{4}$ This corresponds well with the numbers reported by the Danish Medicines Agency (See http://www.medstat.dk), showing that the overall proportion of Danish children aged 10-14 in pharmacological treatment for ADHD was $1.6 \%$ in 2009, which is close to the percentage diagnosed in our data.
} 
Table 1. Summary Statistics Regarding the ADHD diagnosis

\begin{tabular}{lccccccc}
\hline \hline & \multicolumn{3}{c}{ Full Sample } & & \multicolumn{3}{c}{ ADHD (treatment) Sample } \\
\cline { 2 - 4 } \cline { 7 - 9 } Birth Cohort & $\begin{array}{c}\text { Cohort } \\
\text { size }\end{array}$ & $\begin{array}{c}\text { \# diagnosed } \\
\text { with ADHD }\end{array}$ & $\begin{array}{c}\text { \% diagnosed } \\
\text { with ADHD }\end{array}$ & & $\begin{array}{c}\text { Average age } \\
\text { at diagnosis }\end{array}$ & $\begin{array}{c}\% \\
\text { Boys }\end{array}$ & $\begin{array}{c}\% \\
\text { Girls }\end{array}$ \\
\hline 1990 & 21,413 & 218 & 1.02 & & 13.19 & 79.82 & 20.18 \\
1991 & 21,424 & 267 & 1.25 & & 12.83 & 76.40 & 23.60 \\
1992 & 21,833 & 301 & 1.38 & & 12.35 & 78.41 & 21.59 \\
1993 & 21,358 & 317 & 1.48 & & 11.79 & 74.45 & 25.55 \\
1994 & 22,142 & 346 & 1.56 & & 10.84 & 80.92 & 19.08 \\
1995 & 21,976 & 343 & 1.56 & & 10.34 & 81.05 & 18.95 \\
1996 & 21,428 & 331 & 1.54 & & 9.82 & 80.97 & 19.03 \\
1997 & 20,725 & 334 & 1.61 & & 9.33 & 84.43 & 15.57 \\
\hline All cohorts & 172,299 & 2,457 & 1.43 & & 11.16 & 79.69 & 20.31 \\
\hline \hline
\end{tabular}

It is seen from Table 1 that the percentage of a cohort diagnosed with ADHD increases over time while the average age at diagnosis falls. This possibly reflects the increased focus on children with ADHD which implies that more children are diagnosed and the disorder is recognised earlier in the child's life than previously. The average age at the time of the ADHD diagnosis is approximately 11 years. Table 1 also demonstrates the higher prevalence of ADHD among boys with a gender ratio in the sample of approximately $4: 1$. Since the ADHD disorder is likely to present itself differently in boys and girls, the impact on parents' relationship stability and labour market behavior is therefore likely to differ depending on the gender of the child with ADHD. We therefore investigate possible gender differences in the impact of ADHD.

\section{Causes of ADHD and Symptoms Associated with ADHD}

The aetiology of ADHD has not yet been clearly identified, but genetic factors are believed to play a very important role. Faraone et al. (2005) document that twin studies estimate the heritability of ADHD to be $76 \%$, which shows the highly heritable nature of the disorder. Besides genetic factors, studies indicate that some biological factors that negatively affect brain development in the prenatal and perinatal life may be risk factors for ADHD. These include maternal smoking (Linnet et al., 2003), alcohol consumption during pregnancy (Mick et al., 2002a), and low birth weight (Mick et al., 2002b). Furthermore, pregnancy and birth complications also seem to predispose for ADHD. Some studies show that the interplay between genetic and environmental factors are important, for example the risk associated 
with maternal smoking during pregnancy may be higher if the child is genetically disposed to ADHD (Laucht et al., 2007). This knowledge about the causes of an ADHD disorder is important to be able to include the most important confounders in the conditioning set.

Diagnosing a child or an adolescent with ADHD is a specialist task and is performed by a psychiatrist or a specialist physician. In Denmark, parents - or in some cases teachers or school nurses - decide whether to seek a diagnosis. This typically involves a visit to the family's general practitioner (GP) who serves as a gatekeeper for specialist treatment. If he agrees with the indications he refers to a specialist at a general hospital or at a private clinic. Consultations with the GP are free of charge (for the parents) as are those with specialist physicians when equipped with a reference from the GP, and the GP is compensated for the reference. Whether patients end up with a specialist employed at general hospitals or at private clinics depends on whether the psychiatric hospitals or wards are overbooked. It is possible to consult with a specialist at a private clinic without a GP reference but then the parents must pay the costs themselves.

The child or adolescent must fulfil a number of diagnostic criteria according to WHO's classification scheme, ICD-10 (World Health Organization, 1992). The core symptoms associated with the disorder are attention deficiencies, hyperactivity, and impulsiveness. To be diagnosed with ADHD, the core symptoms must be present before the age of 7 and the symptoms must be present in at least two environmental settings e.g. home and school (Child and Youth Psychiatric Society, 2008). Actually, Auerbach et al. (2004) suggest that symptoms are present in infants with a familial risk of ADHD. They tend to have a higher temper, be easily moved to tears, and are less able to calm themselves. In addition, a small study by Thunstrom (2002) suggests that poor sleep patterns in infancy and early childhood is associated with a subsequent ADHD disorder. Thus, the impact on parents' labor supply and relationship may occur early in the child's life and long before the actual diagnosis.

Besides the core symptoms, children with ADHD often suffer from comorbid problems such as depression, anxiety, behavioral problems, tics, social dysfunction, as well as literacy and other learning problems (Child and Youth Psychiatric Society, 2008). 


\section{Treatment of ADHD}

The treatment possibilities for children with ADHD include pharmacological treatment with central nervous system stimulants ${ }^{5}$ or psychological treatment such as parent training or social skills training (Child and Youth Psychiatric Society, 2008). In Denmark, both types of treatments are offered free of charge if the costs are non-trivial according to some predefined limit, although parents or children may of course refuse treatment. Several randomized controlled studies confirm that the use of stimulants is effective in reducing the core symptoms of ADHD and associated impairments including social skills, family functioning, and aggressive outbursts (Spencer et al. 1996; Pliszka et al., 2006). According to the MTA (1999) study, psychological treatment is also effective but less so than stimulant medication in reducing core symptoms.

Since treatment may reduce the core symptoms of ADHD it may change the quality of life of the child and ease the lives of parents. The amount of stress and worry experienced by the parents may be reduced and the care-giving burden may also be relieved. This may in turn improve the relationship between the parents and thereby reduce the risk of relationship dissolution. Moreover, less stress and lower time requirements may imply that the parents once again can invest more time in other activities including work. It is however worth noticing that despite some of the positive effects of treatment, the treatment still only mitigates the core symptoms, thus having a child with ADHD who receives medication for the disorder may still require more parental time than a child without ADHD. This paper is concerned with effects of ADHD per se and we do not address the possible impact of pharmacological and psychological treatment on parents' labor supply and risk of relationship disruption here.

\section{DATA AND DESCRIPTIVE STATISTICS}

\section{Data Source}

Our main data stem from the Danish Psychiatric Central Register; see Munk-Jørgensen and Mortensen (1997) for a detailed description. These data include information about psychiatric history and diagnoses for parents and children diagnosed at Danish general hospitals before 2010. We augment this data source with information about standard

\footnotetext{
${ }^{5}$ Methylphenidate is the most common pharmacological treatment, better known under the brand name Ritalin. A recent development is Concerta; a once daily extended release form of methylphenidate. Please consult NICE (2006) and Banaschewski et al. (2006) for details on recommended pharmacological treatment.
} 
background variables: We apply demographic, income, labor market, and educational characteristics dating back to 1980 as well as information about which people share the same address while being registered as married or cohabiting. We obtain information about exact birth dates from the fertility register which also includes information about birth weight, $\mathrm{APGAR}^{6}$, and smoking during pregnancy.

Most empirical work investigating the effects of child health on parents' relationship and labor market behavior rely on self-reported retrospective health measures as collected in the Child Health Supplement to the National Health Interview Survey (NHIS-CH) or on the Fragile Families Study for US children (e.g. Mauldon, 1992; Corman and Kaestner, 1992; Joesch and Smith, 1997; and Reichman et al., 2004). This may induce bias because the variables of main interest are potentially affected by recall bias (up to 15 years after birth) and by parents' perception of the child's and own health conditions (e.g. Mauldon, 1992; Corman and Kaestner, 1992). Therefore, a particular advantage of our administrative data is access to actual diagnosis data. As described above, obtaining a diagnosis requires a thorough processing by a psychiatrist or specialist physician, which means that we can avoid basing child health on potentially biased self-reported measures. According to the Child and Youth Psychiatric Society (2008), there has been a considerable development in the quality of diagnostic tools in recent years, which reduces the extent of incorrect diagnoses. However, as mentioned earlier, we only observe individuals who are diagnosed at a general hospital. Another potential drawback of this type of data is that some children may suffer from ADHD without being diagnosed, and therefore, are not registered in the available data. Two points are worth mentioning in this respect. First of all, since the severity of the core symptoms of ADHD varies, it is plausible that the core symptoms of children diagnosed with ADHD are more severe than in undiagnosed cases. Thus, the estimated treatment effect is an upper bound estimate of the effect of having a child with ADHD. Secondly, characteristics of parents of a child diagnosed with ADHD may differ from those of parents of a child with ADHD but without a diagnosis. To the extent that these characteristics overlap with our conditioning set, we partly account for that.

\section{Sample Selection}

\footnotetext{
${ }^{6}$ The APGAR score is a grading of the health of the newborn child immediately after birth on the following five criteria: Appearance, Pulse, Grimace, Activity, and Respiration which ranges from zero to 10, where a lower score indicates worse health and 7-10 reflects a normal score.
} 
Our sample includes parents of children born between 1990 and 1997. Information about children's psychiatric diagnoses is not available until 1994 yet because it is extremely rare that children are diagnosed before age 4, we include children born as early as 1990 . Considering children born in 1997 or earlier allows us to analyze effects on parents' outcomes in a considerable period (ten years) after the birth of a child.

Among these individuals, we select parents who are married or cohabiting at the time of the first childbirth. Cohabiting couples are included in addition to married couples, since the former has become a widespread family form. We provide a sensitivity analysis below.

We focus our analysis on the firstborn child of the parents. First of all, looking at the effect of the disorder among all children would complicate matters because the disorder is heritable, and therefore, the prevalence is correlated among siblings. Secondly, it would force us to make more specific assumptions about when the disorder presents itself. Finally, we are concerned that subsequent fertility decisions are affected by the health of the firstborn which would lead to skewed sample selection. This selection criterion implies that the estimated total effect of having a firstborn child with ADHD also captures effects running through a possible ADHD disorder of a younger sibling in addition to other possible indirect effects.

Strictly speaking, the focus is on the firstborn child of the mother, which implies that the father may have children from previous relationships. Table 2 summarizes the consequences of our selection criteria. We only include parents for whom the father's children from previous relationships do not live in the same household as him. This restriction is imposed to take into account that the presence of stepchildren in the household does not to the same degree affect the actions and decisions of the mother and the biological father. But in order to limit the number of discarded observations, we keep those for which the father's child(ren) from previous relationship(s) live with the biological mother. Furthermore, we exclude parents for whom the first pregnancy resulted in multiples and parents where one (or both) of them passed away or are abroad within the ten-year time frame. Finally, we exclude observations with missing information on parents' civil status and labor supply. Altogether these restrictions result in a sample of 172,299 observations of which 2,457 have a firstborn child diagnosed with ADHD and 169,842 have a firstborn child without ADHD. The same sample is used for both the civil status and the labor supply analysis. 
Table 2. Sample Selection Criteria and Sample Size

\begin{tabular}{|c|c|c|}
\hline & Reduction & $\begin{array}{l}\text { Number } \\
\text { of Parents }\end{array}$ \\
\hline Observations of married or cohabiting parents who gave birth to their first child between 1990 and 1997 & & 200,945 \\
\hline Father's children from previous relationships living in the same households as him & 2,698 & 198,247 \\
\hline Deceased parent within the ten-year time frame & 2,377 & 195,870 \\
\hline Multiples (firstborns) & 3,367 & 192,503 \\
\hline Parents abroad within the ten-year time frame & 4,151 & 188,352 \\
\hline Missing information on civil status or labor supply within the ten-year time frame & 16,053 & 172,299 \\
\hline
\end{tabular}

\section{Defining the Treatment Variable: Children with ADHD}

We classify a child to have ADHD if the child is diagnosed with any of the diagnoses within the category hyperkinetic disorders in ICD-10 in the period after birth and up until 2010, which is our most recent data point. As discussed above, the ICD-10 scheme does not apply the diagnosis Attention-Deficit/Hyperactivity Disorder which is used in the American diagnosis scheme DSM-IV. Instead the scheme applies the diagnosis category Hyperkinetic disorders (F90) with the diagnoses disturbance of activity and attention (F90.0), hyperkinetic conduct disorder (F90.1), other hyperkinetic disorders (F90.8), and hyperkinetic disorder, unspecified (F90.9). ${ }^{7}$

If the child is diagnosed with ADHD at some point in time before 2010, the parents belong to the treatment group. In other words, even though the child is not diagnosed within the first ten years of its life, which is our window of analysis, the parents will still belong to the treatment group if the child is diagnosed with ADHD later on (but before 2010). As mentioned earlier, the diagnosis is given if the symptoms were present before the age of 7 .

\section{The Outcome Variables: Civil Status and Labor Supply}

In both the civil status and labor supply analysis, we examine the effect of having a firstborn child with ADHD in a ten-year time frame after the birth of the child. We therefore construct dependent variables for each year in the time frame under consideration. In the civil status analysis, the outcome variable of interest is the civil status of the child's biological parents in a given year. The dependent variable is equal to one if the child's biological parents are divorced or no longer cohabiting in a given year and equal to zero otherwise. ${ }^{8}$ The

\footnotetext{
${ }^{7}$ See details in WHO (1992).

${ }^{8}$ The parents may move in with a new partner or remarry in the time period under consideration. Similarly, they may breakup with the new partner. But the focus is only on a possible break-up between the child's biological parents.
} 
parents are registered as being divorced or non-cohabiting if they no longer live at the same address. Accordingly, parents who are married but not living together will be classified as divorced, but we believe this concerns few couples.

In the labor supply analysis, we explore both the intensive labor supply of the mother and father as well as the extensive labor supply of the mother. The intensive decision reflects the amount of time the individual spends on the labor market whereas the extensive decision reflects whether the individual is employed or not. To measure the intensive labor supply, we calculate the number of full-time working days per year ranging from 0 to 260 days. To measure the extensive labor supply decision, we construct the dependent variable, which is equal to one if the mother is employed in a given year (works at least one day in a given year) and equal to zero if the mother is non-employed (does not work at all in a given year). Hence, non-employed mothers therefore include both mothers who do not participate in the labor market and mothers who are unemployed.

Figure 1 depicts parents' civil status 0 to 10 years after the first childbirth in the treatment and control group. The figure shows that a larger share of parents' with a child with ADHD are divorced or no longer cohabiting in each of the ten years after the childbirth compared to parents' without a child with ADHD. Ten years after childbirth, $28 \%$ of parents who did not have a child with ADHD are divorced compared to $49 \%$ of parents who did have a child with ADHD. Thus, parents with a child suffering from ADHD have a $75 \%$ higher probability of having dissolved their relationship 10 years after childbirth. This gap corresponds well with the gaps found by Hartley et al. (2010) and Wymbs et al. (2008) of about $70-80 \%$ for ASD and ADHD, respectively.

Figure 2 depicts the intensive labor supply of mothers and fathers in a ten-year time frame after the first childbirth in the treatment and control group. ${ }^{9}$ The figures reveal that mothers and fathers in the treatment group in general work less than those in the control group, since a level difference is present already before the first childbirth. Therefore, it is important to control for pre-birth labor supply in the empirical analysis. For mothers, the level difference seems to decrease slightly in the first part of the period and then to increase from year 5. For fathers, the level difference expands slightly from year 2 and remains rather stable for the rest of the period under consideration. Ten years after birth, the gap is about 23 and 13 days per year for mothers and fathers, respectively. Before conditioning on any covariates, these descriptive figures suggest that mothers of a child with ADHD may reduce

\footnotetext{
${ }^{9}$ The figures also include parents who supply zero days of labor in a year, i.e. parents who are non-employed.
} 
the number of working days in the latter part of the ten-year time frame under consideration compared to mothers of a child without ADHD, while fathers may reduce the time spent on the labor market earlier than mothers.

\section{Figure 1. Parents' Civil Status after First Childbirth}

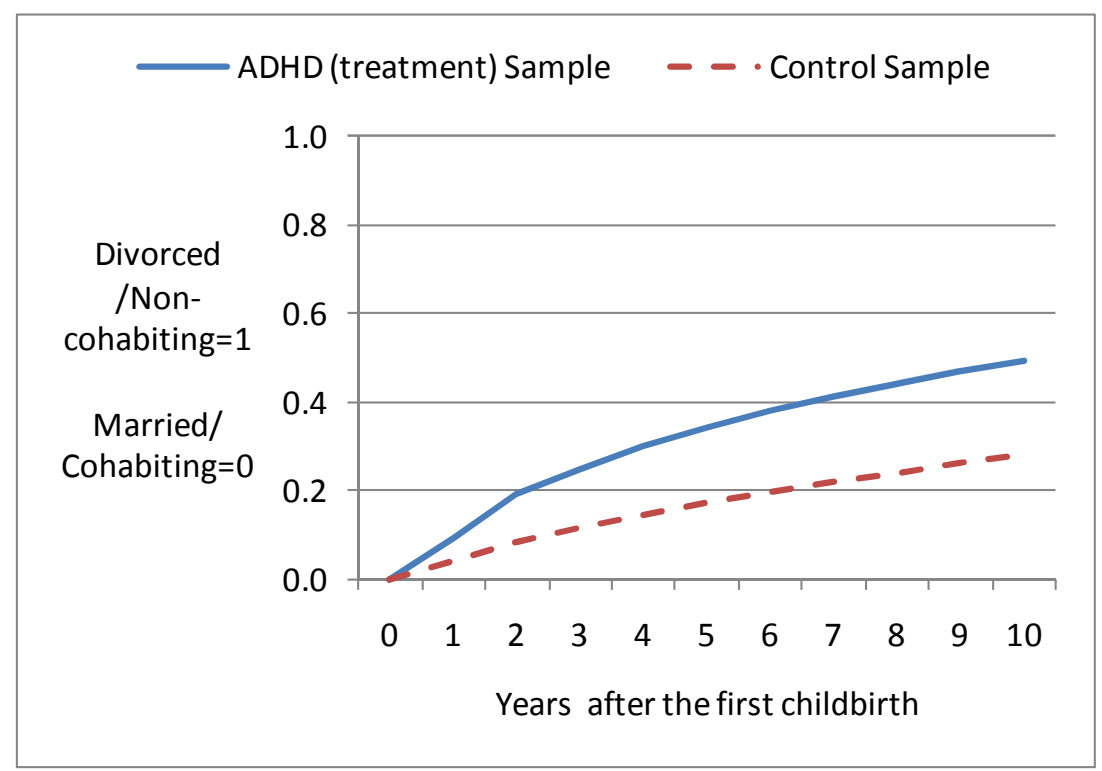

The final outcome variable in the labor supply analysis is illustrated in Figure 3 that shows mothers' extensive labor supply in a ten-year time frame after the first childbirth. Throughout the ten-year time frame, a larger share of mothers in the treatment group is nonemployed compared to mothers in the control group. But similar to the intensive labor supply of the mother, the difference is already present from childbirth. The level difference seems to decrease slightly until year 5 after which it increases slightly.

Of course, these differences in outcomes may just be explained by differences in observed and unobserved characteristics of families with and without children with ADHD. The next section will explore the degree to which observable characteristics vary. Is it, for example, just the case that parents' of children with ADHD have other characteristics that make them more likely to divorce and less likely to work in the first place? 


\section{Figure 2. Intensive Labor Supply after first Childbirth}
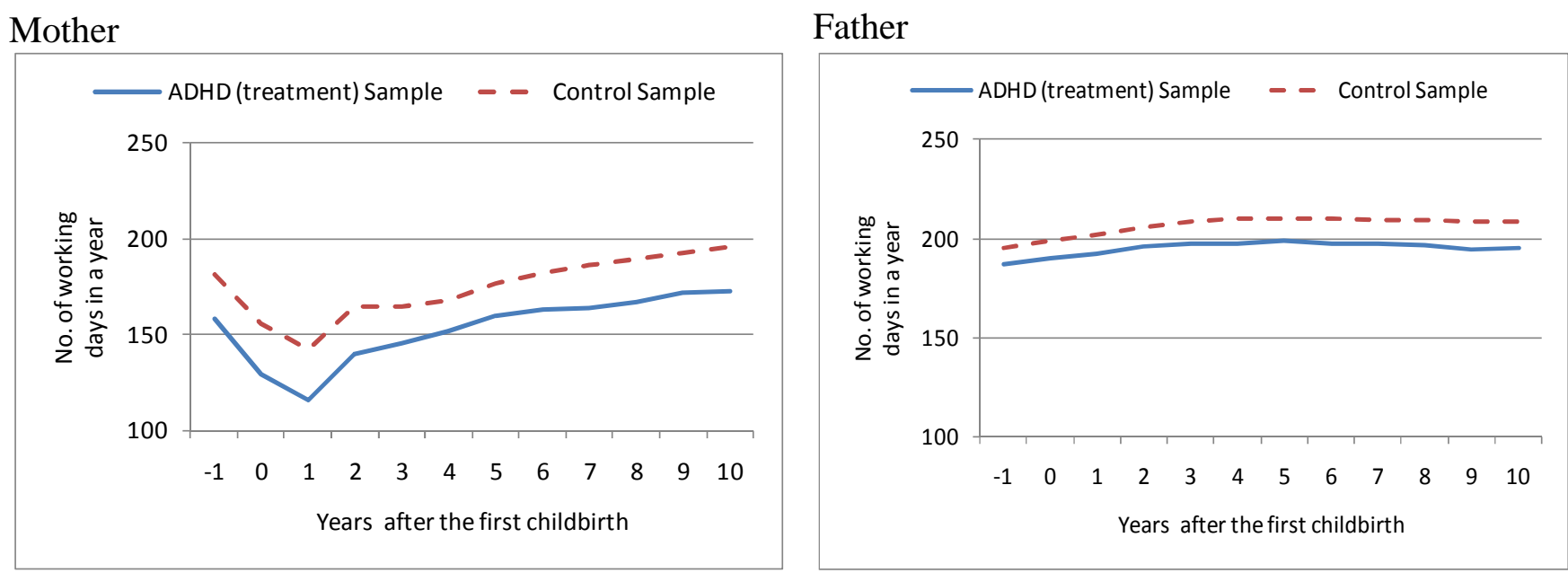

Note: Year 0 is the year of the first childbirth

Figure 3. Extensive Labor Supply after first Child Birth (Mother)

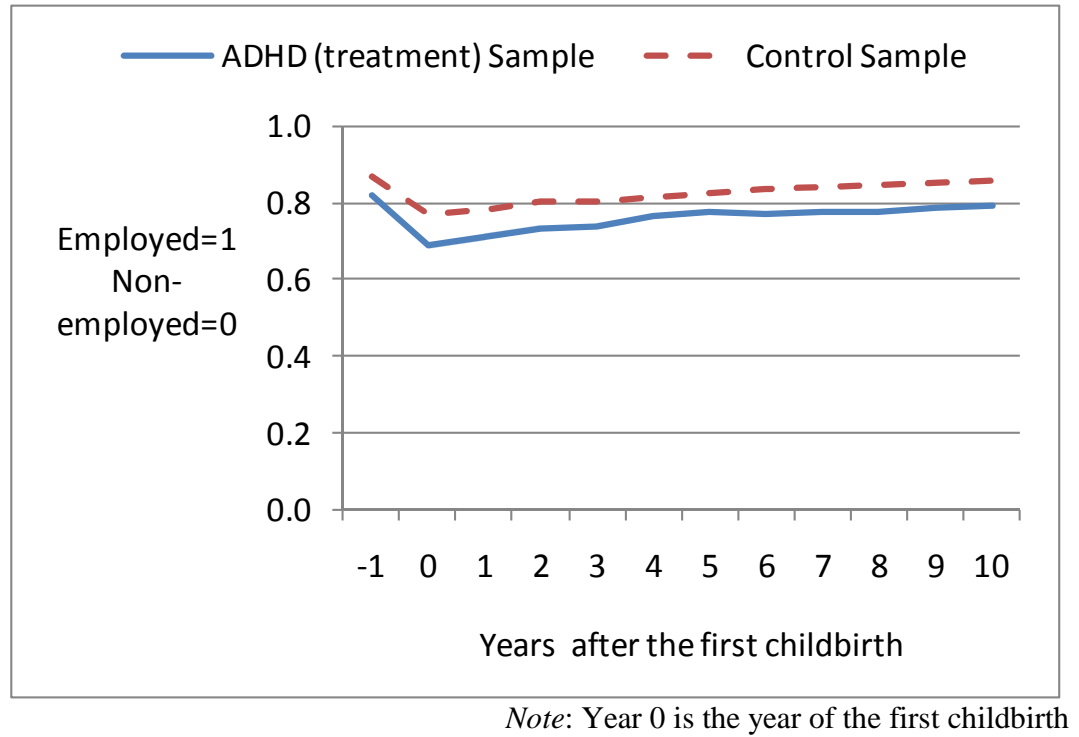

\section{The Conditioning Set: Characterizing Families with ADHD Children}

In order to identify the parameter of interest, it is important to carefully choose the covariates. It is essential to include variables that are surely measured before the presence of any ADHD symptoms and which are likely related to both the outcome of interest and the treatment. We measure all variables in the conditioning set before or at the time of the birth. 
Both genetic and biological factors are believed to be important determinants of ADHD. In particular, the heritable nature of ADHD makes it important to adjust for potential genetic factors. Therefore, we control for whether the parents have any psychiatric diagnosis in the period up until the first childbirth. This may affect their ability to supply labor and to sustain a stable relationship with their partner. To capture biological factors that may negatively affect the child's brain development in the prenatal and perinatal life, we include several health dummies of the child at birth in the conditioning set. These are: low birth weight (less than 2,500 gram), complications at birth and in the perinatal period ${ }^{10}$, gestation length, and APGAR score. Moreover, we include variables reflecting the health of the mother, whether she smoked during pregnancy, and her age. All of these variables can increase the risk of low birth weight and birth complications. ${ }^{11}$ Finally, we have an interaction term capturing whether any of the parents have a psychiatric diagnosis and whether the mother smoked during pregnancy. This should help capture the interplay between genetic and environmental factors, since risk associated with maternal smoking during pregnancy is considered to be higher if the child is genetic disposed to ADHD (Laucht et al., 2007). In general, it is plausible that the health measures of the child at birth also affect the outcome variables of interest, in particular in the first part of the child's life. Having a newborn child in poor health can be a traumatic event for the parents and the poor health of the newborn may have long lasting effects into childhood.

The above-mentioned variables may directly affect both outcomes and the likelihood of having a child with ADHD. We also include variables that to a greater extent serve as proxies. In other words, they may not directly affect the risk of having a child with ADHD, but can proxy relevant confounders and thus indirectly explain treatment. Among these are variables describing income, education, working days, and durations of unemployment. These variables may be important determinants for relationship disruption and labor supply or they may indirectly affect the risk of having a child with ADHD or seeking a diagnosis.

We include a variable measuring whether both parents are immigrants as they might supply a different amount of labor and have a different risk of relationship disruption than natives due to cultural differences as well as different predisposition to develop ADHD or different propensity to seek a diagnosis than natives due to possible cultural differences.

\footnotetext{
${ }^{10}$ See Appendix A for a classification of complications at birth and in the perinatal period.

${ }^{11}$ To capture the health of the mother, we control for any respiratory or heart diseases in the period up until the birth of the child. Poor health of the mother may not only affect the likelihood of birth complications and low birth weight, it may in general be a common trait in mothers of a child with ADHD and thus capture relevant differences between the treatment and control group and through that explain the probability of having a child with ADHD. For this reason, we also include measures for the father's respiratory and heart diseases up until the birth of the child.
} 
In addition, we include variables that measure whether the father and mother have previously been married, whether the father has any children from previous relationships, whether the parents were married at the time of the first childbirth, and a variable that measures for how long parents have lived together before the birth of the child in question. If parents of a child with ADHD have more unstable relationships due to a possible psychiatric disorder or other common traits, then the inclusion of these variables may indirectly explain treatment. Moreover, the variables can also affect the risk of relationship dissolution. The variable measuring whether parents are married at the time of the first childbirth should also capture that relationships of couples who are married at the time of the first childbirth may be more stable than relationships of couples who are cohabiting. 
Table 3. Descriptive Statistics

\begin{tabular}{|c|c|c|c|c|c|c|}
\hline \multirow[t]{2}{*}{ Variable } & \multicolumn{2}{|c|}{$\begin{array}{l}\text { Parents of a firstborn } \\
\text { child with ADHD }\end{array}$} & \multicolumn{2}{|c|}{$\begin{array}{l}\text { Parents of a firstborn } \\
\text { child without ADHD }\end{array}$} & \multicolumn{2}{|c|}{ Full Sample } \\
\hline & Mean & Std. Dev. & Mean & Std. Dev. & Mean & Std. Dev. \\
\hline \multicolumn{7}{|l|}{ Child: } \\
\hline Birth weight less than 2,500 grams $(0 / 1)$ & $\mathbf{0 . 0 2 7}$ & & 0.012 & & 0.012 & \\
\hline Gestation length (weeks) & 38.803 & 5.250 & 39.224 & 4.472 & 39.218 & 4.484 \\
\hline Gestation length (weeks) missing $(0 / 1)$ & 0.015 & & 0.011 & & 0.011 & \\
\hline Complications at birth $(0 / 1)$ & 0.309 & & 0.280 & & 0.280 & \\
\hline Complications in the perinatal period $(0 / 1)$ & 0.091 & & 0.055 & & 0.056 & \\
\hline 5-minute APGAR score & 9.581 & 1.588 & 9.715 & 1.291 & 9.713 & 1.296 \\
\hline 5-minute APGAR score missing $(0 / 1)$ & 0.010 & & 0.008 & & 0.008 & \\
\hline Boy $(0 / 1)$ & 0.797 & & 0.507 & & 0.512 & \\
\hline \multicolumn{7}{|l|}{ Mother: } \\
\hline Age at child birth & 25.967 & 4.319 & 27.285 & 4.080 & 27.266 & 4.086 \\
\hline Primary school (0/1) & 0.386 & & 0.217 & & 0.219 & \\
\hline High school (0/1) & 0.102 & & 0.129 & & 0.128 & \\
\hline Vocational education $(0 / 1)$ & 0.357 & & 0.394 & & 0.393 & \\
\hline Short further education $(0 / 1)$ & 0.035 & & 0.042 & & 0.042 & \\
\hline Medium further education $(0 / 1)$ & 0.092 & & 0.152 & & 0.151 & \\
\hline Long further education $(0 / 1)$ & 0.022 & & 0.061 & & 0.060 & \\
\hline Education missing $(0 / 1)$ & 0.006 & & 0.006 & & 0.006 & \\
\hline Duration of unemployment (weeks)* & 8.366 & 13.723 & 5.947 & 12.019 & 5.982 & 12.048 \\
\hline Gross income $(\mathrm{dkk})^{*}$ & 178908 & 82877 & 201816 & 87843 & 201490 & 87816 \\
\hline No. of working days in a year* & 158.06 & 103.25 & 181.10 & 99.07 & 180.77 & 99.17 \\
\hline Psychiatric diagnosis $(0 / 1)$ & 0.046 & & 0.022 & & 0.023 & \\
\hline Heart disease $(0 / 1)$ & 0.020 & & 0.019 & & 0.019 & \\
\hline Respiratory disease $(0 / 1)$ & 0.175 & & 0.112 & & 0.113 & \\
\hline Smoker $(0 / 1)$ & 0.045 & & 0.025 & & 0.025 & \\
\hline Smoker missing $(0 / 1)$ & 0.149 & & 0.181 & & 0.180 & \\
\hline Smoker*Psychiatric diagnosis (parents) $(0 / 1)$ & 0.008 & & 0.003 & & 0.003 & \\
\hline Married before $(0 / 1)$ & 0.030 & & 0.025 & & 0.025 & \\
\hline \multicolumn{7}{|l|}{ Father: } \\
\hline Age at child birth & 29.007 & 5.305 & 29.900 & 5.140 & 29.887 & 5.143 \\
\hline Primary school (0/1) & 0.353 & & 0.218 & & 0.220 & \\
\hline High school $(0 / 1)$ & 0.056 & & 0.081 & & 0.081 & \\
\hline Vocational education $(0 / 1)$ & 0.441 & & 0.449 & & 0.448 & \\
\hline Short further education $(0 / 1)$ & 0.046 & & 0.068 & & 0.068 & \\
\hline Medium further education $(0 / 1)$ & 0.050 & & 0.090 & & 0.090 & \\
\hline Long further education $(0 / 1)$ & 0.036 & & 0.081 & & 0.080 & \\
\hline Education missing $(0 / 1)$ & 0.018 & & 0.012 & & 0.013 & \\
\hline Duration of unemployment (weeks)* & 5.843 & 11.772 & 4.121 & 10.090 & 4.146 & 10.118 \\
\hline \# of observations & 2,457 & & 169,842 & & 172,299 & \\
\hline
\end{tabular}

Note: Bold indicates a significant difference between the treatment and control group at the $5 \%$ level.

* Measured in the year prior to the birth of the firstborn child. Gross income is in 2004 prices.

Table 3. Descriptive Statistics (Continued) 


\begin{tabular}{|c|c|c|c|c|c|c|}
\hline \multirow[t]{2}{*}{ Variable } & \multicolumn{2}{|c|}{$\begin{array}{l}\text { Parents of a firstborn } \\
\text { child with ADHD }\end{array}$} & \multicolumn{2}{|c|}{$\begin{array}{l}\text { Parents of a firstborn } \\
\text { child without ADHD }\end{array}$} & \multicolumn{2}{|c|}{ Full Sample } \\
\hline & Mean & Std. Dev. & Mean & Std. Dev. & Mean & Std. Dev. \\
\hline Gross income below 170,000dkk (0/1) & 0.233 & & 0.166 & & 0.167 & \\
\hline Gross income between $170,000-200,000 \mathrm{dkk}(0 / 1)$ & 0.082 & & 0.068 & & 0.068 & \\
\hline Gross income between $200,000-230,000 \mathrm{dkk}(0 / 1)$ & 0.133 & & 0.103 & & 0.104 & \\
\hline Gross income between $230,000-260,000 \mathrm{dkk}(0 / 1)$ & 0.156 & & 0.150 & & 0.150 & \\
\hline Gross income between $260,000-290,000 \mathrm{dkk}(0 / 1)$ & 0.127 & & 0.143 & & 0.143 & \\
\hline Gross income between $290,000-320,000 \mathrm{dkk}(0 / 1)$ & 0.085 & & 0.108 & & 0.108 & \\
\hline Gross income between 320,000 - 350,000dk (0/1) & 0.060 & & 0.074 & & 0.074 & \\
\hline Gross income above $350,000(0 / 1)$ & 0.124 & & 0.188 & & 0.187 & \\
\hline No. of working days in a year* & 186.892 & 96.891 & 194.963 & 95.899 & 194.848 & 95.918 \\
\hline Psychiatric diagnosis $(0 / 1)$ & 0.039 & & 0.023 & & 0.023 & \\
\hline Heart disease $(0 / 1)$ & 0.030 & & 0.024 & & 0.024 & \\
\hline Respiratory disease $(0 / 1)$ & 0.112 & & 0.091 & & 0.091 & \\
\hline Married before $(0 / 1)$ & 0.072 & & 0.057 & & 0.057 & \\
\hline Child (children) with another mother (mothers) $(0 / 1)$ & 0.115 & & 0.085 & & 0.085 & \\
\hline \multicolumn{7}{|l|}{ Father and mother: } \\
\hline Married at child birth $(0 / 1)$ & 0.403 & & 0.479 & & 0.478 & \\
\hline Years together at childbirth & 3.729 & 2.605 & 4.335 & 2.725 & 4.326 & 2.724 \\
\hline Immigrants (one or both parents) $(0 / 1)$ & 0.050 & & 0.061 & & 0.061 & \\
\hline Northern Jutland $(0 / 1)$ & 0.065 & & 0.095 & & 0.095 & \\
\hline Central Jutland (0/1) & 0.227 & & 0.218 & & 0.218 & \\
\hline Southern Jutland $(0 / 1)$ & 0.234 & & 0.247 & & 0.247 & \\
\hline Copenhagen $(0 / 1)$ & 0.346 & & 0.301 & & 0.302 & \\
\hline Zealand $(0 / 1)$ & 0.127 & & 0.139 & & 0.139 & \\
\hline \multicolumn{7}{|l|}{ Year-dummies: } \\
\hline 1990 & 0.089 & & 0.125 & & 0.124 & \\
\hline 1991 & 0.109 & & 0.125 & & 0.124 & \\
\hline 1992 & 0.123 & & 0.127 & & 0.127 & \\
\hline 1993 & 0.129 & & 0.124 & & 0.124 & \\
\hline 1994 & 0.141 & & 0.128 & & 0.129 & \\
\hline 1995 & 0.140 & & 0.127 & & 0.128 & \\
\hline 1996 & 0.135 & & 0.124 & & 0.124 & \\
\hline 1997 & 0.136 & & 0.120 & & 0.120 & \\
\hline \# of observations & 2,457 & & 169,842 & & 172,299 & \\
\hline
\end{tabular}

Note: Bold indicates a significant difference between the treatment and control group at the $5 \%$ level.

* Measured in the year prior to the birth of the firstborn child. Gross income is in 2004 prices.

Finally, we include regional dummies and year dummies to account for possible regional and time differences. To get an overview of observed differences between the two groups, Table 3 shows descriptive statistics for the full sample and for parents with and without a firstborn child with ADHD. Unless otherwise noted, the characteristics are measured at the time of the first childbirth. ${ }^{12}$ From Table 3 it is clear that the treatment group has significantly different characteristics compared to the control group. Parents of a child

\footnotetext{
${ }^{12}$ We measure income, working days, and duration of unemployment in the year before the birth of the child, since it is plausible that pregnancy and subsequent parental leave would affect these variables (especially for mothers).
} 
with ADHD have lower education, lower gross income, supply less labor, and are more likely to have been unemployed. In addition, mothers of a child with ADHD are younger, smoke more often during pregnancy, and are more likely to have a psychiatric diagnosis as well as a respiratory disease, while fathers are more likely to have a psychiatric diagnosis and a heart disease. ${ }^{13}$ Moreover, fathers of a child with ADHD are more likely to have children from previous relationships and to have been previously married. Furthermore, parents of a child with ADHD have been living together in fewer years and are less likely to be married at the time of the first childbirth and are less likely to be immigrants. In addition, differences in the health of the child at birth are observed in the two groups. In the treatment group a significantly larger share of parents gave birth to a child with low birth weight, experienced complications at birth and in the perinatal period, and had a shorter gestation length. Finally, parents of a child with ADHD are more likely to have a boy reflecting the higher prevalence of ADHD among boys.

Overall, Table 3 indicates that parents of a child with ADHD have less favourable socioeconomic characteristics compared to parents without. The different pattern in civil status and labor supply in Figures 1-3 may partly reflect these differences. Therefore, it is very important to take these characteristics into account when estimating the effect of having a child with ADHD on parents' labor supply and risk of dissolution. Referring to the aetiology of ADHD in the above, we have sufficiently rich data to control for the majority of causes likely to affect the risk of having a child with ADHD. ${ }^{14}$ As argued above, these variables are also likely to affect the outcome variables of interest. Furthermore, we have a broad range of socioeconomic characteristics to capture possible differences between the treatment and control group. However, since the aetiology of ADHD is not yet fully identified we cannot rule out that we might lack some covariates that affect the likelihood of having a child with ADHD and the outcome variables of interest. Moreover, there is always the risk of remaining unobservable differences not sufficiently balanced out when conditioning on the observed covariates. But overall, we are confident that the data are sufficiently rich to reduce the selection bias substantially.

As argued, the conditioning set does not include variables likely to be affected by the presence of a firstborn child with ADHD. It is, though, still of interest to understand how the

\footnotetext{
${ }^{13}$ Many parents in the sample are diagnosed after the birth of the firstborn child. At the beginning of 2010, $18 \%$ of the fathers and $21 \%$ of the mothers of firstborn children diagnosed with ADHD had a psychiatric diagnosis, while $9 \%$ of the fathers and $10 \%$ of the mothers of firstborn children not diagnosed with ADHD had a psychiatric diagnosis. However, we cannot control for this since diagnoses after the birth of the child may be influenced by the presence of a child diagnosed with ADHD.

${ }^{14}$ We lack a measure for the mother's alcohol consumption during pregnancy.
} 
effect materializes. For instance, parents who have a firstborn child diagnosed with ADHD have fewer children on average (1.9 compared to 2.0 ), and - due to the heritable component of the disorder - they are more likely to have younger children who are also diagnosed with ADHD (8\% compared to $1 \%$ ). Therefore, we perform sensitivity checks to understand these potential channels better.

\section{Interactions between Timing of Diagnosis and Outcome Variables}

Before continuing to the formal empirical analysis, we examine the relationship between the timing of the ADHD diagnosis and the outcome variables of interest. Although the time of the ADHD diagnosis of the child is less relevant in our set-up, it could still be of interest to examine its potential impact on parents' labor supply and risk of relationship dissolution. The diagnosis time is likely an important point in time, since the impact of ADHD in children on parents' relationship and labor supply could change following a diagnosis. After a diagnosis, the degree of the core symptoms may ease due to treatment with stimulant medicine or other types of treatment. Moreover, the parents might be relieved to finally get an explanation on their child's unusual behavior which in turn could reduce the stress level and worry experienced by the parents. We therefore graphically analyse how the time of the ADHD diagnosis affects the outcome variables of interest. Figure B1 in Appendix B depicts the civil status and labor supply of the mother before and after the year of the child's ADHD diagnosis. It is seen that the time of the child's ADHD diagnosis does not seem to change the pattern in relationship dissolution (left panel). One possible explanation is that the relationship has been under pressure for an extended period making it difficult to save despite the potential positive effects from the child's ADHD diagnosis and treatment. The picture is, however, different when considering the mother's labor supply before and after the diagnosis year (right panel). In a three-year time period before the ADHD diagnosis, mothers of a child with ADHD spent on average 160 working days on the labor market. After the child is diagnosed with ADHD, the labor supply of mothers gradually increases throughout the remaining period under consideration and slightly more in the year after the diagnosis. This picture may reflect the positive effects on the family when the child's disorder is recognised and diagnosed such that treatment and intervention strategies can be formed. In the period before the diagnosis, the mother may focus more on care-giving activities instead of spending additional time on the labor market. After the diagnosis and possible treatment with stimulant medicine, the mother may have the time and energy available for more market work. This may indicate that the ADHD diagnosis of the child may 
have a positive impact on the mother's labor supply, possibly due to pharmacological or psychological treatment of the child.

\section{THE IMPACTS OF ADHD IN CHILDREN ON PARENTAL OUTCOMES}

This section presents our results from our formal analysis. We estimate effects of having a child with ADHD on parents' propensity to dissolve their relationship and parental labor supply during the first ten years after the birth of the child. We employ standard regression techniques while conditioning on our rich set of observables discussed above. ${ }^{15}$ The first part of the section presents our main results. We then provide a range of sensitivity analyses and robustness checks.

\section{Main Results}

Table 4 shows our main estimation results. We see that parents of children with ADHD are significantly more likely to dissolve their relationship than other couples and that the effects increase over time. ${ }^{16}$ The size of the effects is generally large relative to the share of couples dissolving, see Figure 1 above. Already one year after birth, the probability of having dissolved the relationship is 1 percentage point higher for parents of a child suffering from ADHD than for other parents, while the probability is 13 percentage points higher when the child is 10 years old. These results are not high compared to previous epidemiological studies. Reichman et al. (2004) report a 10 percentage point higher dissolution rate already 12-18 months after birth.

Effects on labor supply are also generally negative but most of the impact is seen on the intensive margin. For mothers, the effect increases over the course of the ten-year period, and at the end of the period the marginal impact is a reduction at the intensive margin of about 58 days per year (out of a maximum of 260 working days) and a reduction at the extensive margin of about 2 percentage point. In comparison, Corman et al. 2005 find an employment reduction due to poor child health of 3 hours per week at the intensive margin and 8 percentage points at the extensive margin. For fathers, the effect is a lower reduction of 45-6 days per year.

\footnotetext{
${ }^{15}$ We have replicated our results using propensity score matching and we have estimated a Cox proportional hazard for relationship dissolution. These results are available on request.

${ }^{16}$ The increasing estimates over time reflect to some extent the accumulative nature of the dependent variable. Seen over the ten-year time period, the dependent variable is equal to zero until the time of dissolution where it changes to one and remains equal to one for the remaining time periods.
} 
The difference between ours and previous studies may to some extent be explained by the different health conditions studied and by the different institutional contexts of Denmark versus the US. However, we suspect that a great extent of the gap is related to the fact that we have access to a richer conditioning set which accounts for the systematic differences between parents of children suffering from the specific disorder considered (here: ADHD) and other parents. In Table B1 in Appendix B, we show the full set of results.

Table 4. The Effect of Having a Child with ADHD on Parents' Outcomes 1-10 Years after Child Birth, 2,457 treated and 169,842 non-treated

\begin{tabular}{|c|c|c|c|c|c|c|c|c|}
\hline \multirow{3}{*}{$\begin{array}{l}\text { Years After } \\
\text { Child Birth }\end{array}$} & \multicolumn{2}{|c|}{ Relationship Dissolution } & \multirow{2}{*}{\multicolumn{2}{|c|}{$\begin{array}{c}\text { Intensive Labor Supply } \\
\text { Mother }\end{array}$}} & \multirow{3}{*}{\multicolumn{2}{|c|}{$\begin{array}{c}\text { Intensive Labor Supply } \\
\text { Father } \\
\text { OLS }\end{array}$}} & \multirow{3}{*}{\multicolumn{2}{|c|}{$\begin{array}{c}\text { Extensive Labor Supply } \\
\text { Mother } \\
\text { Probit }\end{array}$}} \\
\hline & & & & & & & & \\
\hline & \multicolumn{2}{|c|}{ Probit } & \multicolumn{2}{|c|}{ OLS } & & & & \\
\hline & Marg.eff. & S.e. & Coeff. & S.e. & Coeff. & S.e. & Marg.eff. & S.e. \\
\hline 1 & $\mathbf{0 , 0 1 0}$ & 0,003 & $-3,973$ & 1,687 & $-2,378$ & 1,539 & $-0,003$ & 0,008 \\
\hline 2 & $\mathbf{0 , 0 3 9}$ & 0,006 & $-4,595$ & 1,833 & $-2,267$ & 1,626 & $-0,005$ & 0,007 \\
\hline 3 & 0,054 & 0,007 & $-0,980$ & 1,901 & $-4,036$ & 1,720 & $-0,003$ & 0,007 \\
\hline 4 & 0,075 & 0,008 & 1,022 & 1,902 & $-6,040$ & 1,793 & 0,003 & 0,007 \\
\hline 5 & 0,088 & 0,009 & 0,047 & 1,918 & $-3,823$ & 1,807 & 0,003 & 0,007 \\
\hline 6 & 0,100 & 0,009 & $-2,919$ & 1,961 & $-5,023$ & 1,830 & $-0,010$ & 0,007 \\
\hline 7 & $\mathbf{0 , 1 0 9}$ & 0,010 & $-5,977$ & 1,977 & $-4,179$ & 1,865 & $-0,011$ & 0,007 \\
\hline 8 & 0,115 & 0,010 & $-6,549$ & 2,009 & $-4,329$ & 1,890 & $-0,018$ & 0,007 \\
\hline 9 & 0,122 & 0,010 & $-5,326$ & 2,017 & $-5,829$ & 1,926 & $-0,014$ & 0,007 \\
\hline 10 & $\mathbf{0 , 1 3 0}$ & 0,010 & $-7,624$ & 2,029 & $-5,120$ & 1,936 & $-0,017$ & 0,007 \\
\hline
\end{tabular}

\section{The Importance of Additional Children in the Family}

As discussed above, families with children diagnosed with ADHD have fewer children than others and this may directly affect the outcomes of interest. It is, however, not innocuous to condition on this information because the decision to have additional children is likely affected by the occurrence of a firstborn child with ADHD. Still, Table 5 documents that our estimates of the effects 10 years after childbirth are not affected by the inclusion of information about presence and number of additional children or information about the presence of younger siblings with ADHD. 
Table 5. The Effect of Having a Child with ADHD on Parents' Outcomes 10 Years after Child Birth w/post-treatment controls, 2,457 treated and 169,842 nontreated

\begin{tabular}{|c|c|c|c|c|c|c|c|c|}
\hline & \multicolumn{2}{|c|}{ Relationship Dissolution } & \multirow{2}{*}{\multicolumn{2}{|c|}{$\begin{array}{c}\text { Intensive Labor Supply } \\
\text { Mother }\end{array}$}} & \multirow{2}{*}{\multicolumn{2}{|c|}{$\begin{array}{c}\text { Intensive Labor Supply } \\
\text { Father } \\
\text { OLS }\end{array}$}} & \multirow{2}{*}{\multicolumn{2}{|c|}{$\begin{array}{c}\text { Extensive Labor Supply } \\
\text { Mother }\end{array}$}} \\
\hline & \multicolumn{2}{|c|}{ Probit } & & & & & & \\
\hline & Marg.eff. & S.e. & Coeff. & S.e. & Coeff. & S.e. & Marg.eff. & S.e. \\
\hline Main spec. & $\mathbf{0 , 1 3 0}$ & 0,010 & $-7,624$ & 2,029 & $-5,120$ & 1,936 & $-0,017$ & 0,007 \\
\hline Main spec. + further children & 0,119 & 0,011 & $-7,366$ & 2,027 & $-4,636$ & 1,931 & $-0,016$ & 0,007 \\
\hline Main spec. + further children w/ ADHD & $\mathbf{0 , 1 3 1}$ & 0,010 & $-6,886$ & 2,031 & $-4,930$ & 1,940 & $-0,015$ & 0,007 \\
\hline
\end{tabular}

Note: Robust standard errors. Bold figures denote significance at the $5 \%$ level.

\section{Heterogeneity in Effects}

Table 6 shows results where we subdivide our sample according to selected characteristics determined before or at the time of birth of the child. Consider first the results by gender of the child. Though the difference is small, it is interesting that the likelihood of divorce is larger if the child with ADHD is a girl, especially since symptoms are more recognizable in boys than in girls. This corresponds well with the literature documenting that divorce rates (i.e. in married couples) are higher in couples where the firstborn is a girl than in couples with a firstborn boy; see e.g. Lundberg, McLanahan and Rose (2007). There is also a tendency for mothers to react more to ADHD in firstborn girls and for fathers to react more to ADHD in firstborn boys. Couples who are married at childbirth react less to having a child with ADHD regardless of the outcome in question: Relationships are, not surprisingly, more stable for this group. The small effects of ADHD on labor market participation are less obvious.

Regarding income differences, most of the action in labor outcomes is seen for the $25-$ $75 \%$ income quantiles. High income couples have a slightly lower propensity to split up due to ADHD in their firstborn 10 years after the birth of the child but the overall conclusion is the same.

There are some regional differences in the size of effects, particularly when considering labor market outcomes. We are particularly interested in the case of Northern Jutland, where the capacity of the general hospital is most limited and the number of registered ADHD diagnoses expected to be underestimated. However, it is difficult to make strong conclusions, because the number of treated cases in each region is very small. Instead as an additional 
robustness check, in Table 7 we study the impact of having an ADHD diagnosis or receiving pharmacological treatment for ADHD (and likely being diagnosed in a private clinic). The estimates are not significantly different although the point estimates tend to be smaller indicating that the cases without a registered diagnosis from a general hospital tend to be less malignant.

Table 6. Heterogeneous Effects of Having a Child with ADHD on Parents' Outcomes 10 Years after Child Birth

\begin{tabular}{|c|c|c|c|c|c|c|c|c|c|}
\hline & \multirow{2}{*}{\multicolumn{2}{|c|}{ Relationship Dissolution }} & \multirow{2}{*}{\multicolumn{2}{|c|}{$\begin{array}{c}\text { Intensive Labor Supply } \\
\text { Mother }\end{array}$}} & \multirow{2}{*}{\multicolumn{2}{|c|}{$\begin{array}{c}\text { Intensive Labor Supply } \\
\text { Father } \\
\text { OLS }\end{array}$}} & \multirow{2}{*}{\multicolumn{2}{|c|}{$\begin{array}{c}\text { Extensive Labor Supply } \\
\text { Mother } \\
\text { Probit } \\
\end{array}$}} & \multirow[t]{2}{*}{ Nobs } \\
\hline & & & & & & & & & \\
\hline All & $\begin{array}{c}\text { Marg.eff. } \\
\mathbf{0 , 1 3 0}\end{array}$ & $\begin{array}{c}\text { S.e. } \\
0,010\end{array}$ & $\begin{array}{l}\text { Coeff. } \\
-7,624\end{array}$ & $\begin{array}{c}\text { S.e. } \\
2,029\end{array}$ & $\begin{array}{l}\text { Coeff. } \\
-\mathbf{5 , 1 2 0}\end{array}$ & $\begin{array}{c}\text { S.e. } \\
1,936\end{array}$ & $\begin{array}{l}\text { Marg.eff. } \\
\mathbf{- 0 , 0 1 7}\end{array}$ & $\begin{array}{c}\text { S.e. } \\
0,007\end{array}$ & 172.299 \\
\hline Boys & 0,128 & 0,012 & $-7,211$ & 2,269 & $-5,989$ & 2,186 & $-0,015$ & 0,008 & 88.141 \\
\hline Girls & $\mathbf{0 , 1 4 3}$ & 0,023 & $-9,475$ & 4,534 & $-1,864$ & 4,173 & $-0,025$ & 0,016 & 84.158 \\
\hline Below the $25 \%$ income quantile & 0,124 & 0,018 & $-3,662$ & 3,626 & $-4,043$ & 3,472 & $-0,008$ & 0,014 & 43.074 \\
\hline Between the $25-50 \%$ income quantile & $\mathbf{0 , 1 3 7}$ & 0,020 & $-12,062$ & 3,998 & $-5,149$ & 3,722 & $-\mathbf{0 , 0 3 1}$ & 0,014 & 43.075 \\
\hline Between the $50-75 \%$ income quantile & 0,140 & 0,022 & $-9,469$ & 4,072 & $-4,719$ & 3,768 & $-0,028$ & 0,014 & 43.076 \\
\hline Above the $75 \%$ income quantile & $\mathbf{0 , 1 0 7}$ & 0,023 & $-3,992$ & 4,365 & $-3,881$ & 4,341 & 0,001 & 0,015 & 43.074 \\
\hline Northern Jutland & 0,119 & 0,041 & $-6,923$ & 7,707 & $-0,771$ & 8,134 & $-0,019$ & 0,028 & 16.318 \\
\hline Central Jutland & $\mathbf{0 , 1 7 5}$ & 0,022 & $-9,603$ & 4,165 & $-9,598$ & 4,148 & $-0,013$ & 0,014 & 37.560 \\
\hline Southern Jutland & $\mathbf{0 , 1 1 0}$ & 0,021 & $-9,572$ & 4,333 & 0,672 & 3,777 & $-0,040$ & 0,016 & 42.494 \\
\hline Copenhagen & 0,106 & 0,018 & $-4,590$ & 3,463 & $-5,153$ & 3,351 & 0,000 & 0,011 & 52.015 \\
\hline Zealand & 0,150 & 0,030 & $-10,311$ & 5,567 & $-9,948$ & 5,305 & $-0,031$ & 0,020 & 23.912 \\
\hline
\end{tabular}

Note: Robust standard errors. Bold figures denote significance at the 5\% level, while italic figures denote significance at the $10 \%$ level. Income quantiles are based on parents' total income in the year before the first childbirth.

Table 7. The Effects of Having a Child with ADHD or ADHD medication on Parents' Outcomes 10 Years after Child Birth

\begin{tabular}{|c|c|c|c|c|c|c|c|c|c|}
\hline & \multicolumn{2}{|c|}{ Relationship Dissolution } & \multicolumn{2}{|c|}{$\begin{array}{c}\text { Intensive Labor Supply } \\
\text { Mother }\end{array}$} & \multicolumn{2}{|c|}{$\begin{array}{c}\text { Intensive Labor Supply } \\
\text { Father }\end{array}$} & \multicolumn{2}{|c|}{$\begin{array}{c}\text { Extensive Labor Supply } \\
\text { Mother }\end{array}$} & Nobs \\
\hline & Marg.eff. & S.e. & Coeff. & S.e. & Coeff. & S.e. & Marg.eff. & S.e. & \\
\hline ADHD or ADHD medication6+ & 0,122 & 0,009 & $-6,884$ & 1,817 & $-4,875$ & 1,747 & $-0,018$ & 0,006 & 172.299 \\
\hline
\end{tabular}

Note: Robust standard errors. Bold figures denote significance at the $5 \%$ level.

\section{CONCLUSION}

We use Danish register-based data for the population of children born in 1990-1997 to investigate the effects on parents of having a child with ADHD. We find that ten years after 
birth, parents of children diagnosed with ADHD have a $75 \%$ higher probability of having dissolved their relationship and a 7-13 \% lower labor supply. By exploiting detailed information about known risk factors behind ADHD, we document that about half of the gap is due to selection. However, a statistically and economically significant gap is left, which is likely related to the impact of high psychic costs of coping with a child with ADHD.

In other words, we find that poor health in terms of ADHD reduces parental socio economic status (SES) by lowering their labor supply (and earnings) and reducing relationship stability. Previous work has shown that there is a strong link between parental SES and child health (Currie, 2009), and that an important reason why children from low SES families suffer from bad health is that they experience more health shocks. In fact, low SES children recover just as fast as high SES children (Currie and Stabile, 2003). In this paper we show that there is also a feedback mechanism where poor child health lowers parental SES.

In accordance with the epidemiological literature on the association between poor child health and parental outcomes, we find that parents of children diagnosed with ADHD have much higher probability of dissolving their relationship and a much lower labor supply than other parents. While the epidemiological literature establishes associations between child health and parents' outcomes, we aim at getting closer to identifying a causal relationship. Associational relations are of great use when one aims at identifying groups at risk of an unfavorable outcome, and thus initiating treatment such as Prevention and Relationship Enhancement Programs (PREP). However, in order to understand the underlying mechanisms explaining individual behavior and decision making, we need to establish causal relationships; the type of relevant interventions is likely to vary depending on whether parental background characteristics drive, for example, the risk of dissolution or whether it is actually the presence of a child with ADHD that is the cause of divorce. With our empirical analysis, we move one step closer to identifying a causal relationship between poor child health and parents' outcomes. Our results rule out causal impact of poor child health of the magnitudes reported in the epidemiological studies.

Our findings imply that it is important to understand how possible treatment strategies may relieve ADHD symptoms, and thus remove some of the adverse effects on parents' relationship stability and labour market outcomes. In this paper, a simple graphical illustration provides some evidence that mothers might increase their labour supply following 
an ADHD diagnosis of the child. This could reflect potential favourable impact on the core ADHD symptoms from treatment with stimulant medicine and/or psychological treatment after the recognition of the child's ADHD disorder. This may in turn have a positive impact on parents' labour supply and on the stability of their relationship. A possible venue for future research could therefore be an examination of how the time of the ADHD diagnosis and possible treatment strategies affect the outcome variables of interest.

\section{Literature}

Aizer, A. (2009), Peer Effects, Institutions and Human Capital Accumulation: The Externalities of ADD. Manuscript. Brown University.

Auerbach, J. G., Atzaba-Poria, N., Berger, A., and Landau, R. (2004), Emerging developmental pathways to ADHD: Possible path markers in early infancy, Neural Plasticity, 11: $29-44$.

Banaschewski, P., D. Coghill, P. Santosh et al. (2006), Long-acting Medications for the Hyperkinetic Disorders. A Systematic Review and European Treatment Guideline. European Child and Adolescent Psychiatry, 15, 476-495.

Becker, G. S., Landes, E. M., and Michael, R. T. (1977), An economic analysis of marital instability, Journal of Political Economy, 85(6): 1141-1188.

Björklund, A., D. Ginther and M Sundström (2007), Family structure and child outcomes in the USA and Sweden, Journal of Population Economics 20:183-201.

Child and Youth Psychiatric Society (2008), Reference Program for Diagnosing and Treating Children and Adolescents with ADHD (Referenceprogram for udredning og behandling af børn og unge med ADHD).

Corman, H. and Kaestner, R. (1992), The effects of child health on marital status and family structure, Demography, 29(3): 389-408. 
Corman, H., Noonan, K., and Reichman, N. E. (2005), Mothers' labor supply in fragile families: The role of child health, Eastern Economic Journal, 31(4): 601-616.

Currie, J. (2009), Healthy, Wealthy, and Wise: Socioeconomic Status, Poor Health in Childhood, and Human Capital Development, Journal of Economic Literature 47(1): 87-122.

Currie, J. and M. Stabile (2003), Socioeconomic Status and Child Health: Why Is the Relationship Stronger for Older Children? American Economic Review, 93 (5): 1813-1823.

Currie, J. and M. Stabile (2006), Child Mental Health and Human Capital Accumulation: The Case of ADHD, Journal of Health Economics, 25, 1094-1118.

Dalsgaard, S., H. S. Nielsen and M. Simonsen (2011), The Effects of Pharmacological Treatment of ADHD on Children's Use of Health Services and Risky Health Behavior. Manuscript.

Faraone, S. V., Perlis, R. H., Doyle, A. E. et al. (2005), Molecular genetics of attentiondeficit/hyperactivity disorder, Biological Psychiatric, 57(11): 1313-23

Fertig, A. R. (2009), Healthy baby, healthy marriage? The effect of children's health on divorce, Working Paper, Georgia University.

Fletcher, J. and B. Wolfe (2008), Child Mental Health and Human Capital Accumulation: The Case of ADHD Revisited, Journal of Health Economics 27, 794-800.

Francesconi, M., S. Jenkins and T. Siedler (2010), Childhood family structure and schooling outcomes: evidence for Germany, Journal of Population Economics 23:12011231.

Gaub, M., and Carlson, C. L. (1997), Gender differences in ADHD: A meta-analysis and critical review, Journal of the American Academy of Child and Adolescent, 36(8): 1036-45. 
Gershon, J. (2002), A meta-analytic review of gender differences in ADHD. Journal of Attention Disorders, 5(3): 143-54.

Gould, E. (2004), Decomposing the effects of children's health on mother's labor supply: Is it time or money? Health Economics, 13(6): 525-541.

Green, H., McGinnity, A., Meltzer, H., et al. (2005), Mental Health of Children and Young People in Great Britain, 2004. A survey carried out by the Office for National Statistics on behalf of the Department of Health and the Scottish Executive. Basingstoke: Palgrave Macmillan.

Hartley, S.H., E. T. Barker, M. M. Seltzer, et al. (2010),'The Relative Risk and Timing of Divorce in Families of Children With an Autism Spectrum Disorder." Journal of Family Psychology 24 (4): 449-457.

Joesch, J. M. and Smith, K. R. (1997), Children's health and their mothers' risk of divorce or separation, Social Biology 44(3-4): 159-69.

Kravdal, Ø., Sigle-Rushton, W., and Steele, F. (2009), Consequences of family disruption on children's educational outcomes in Norway, Demography 46(3): 553-574.

Laucht, M., Hohm, E., Esser, G., Schmidt, M. H., and Becker, K. (2007), Association between ADHD and smoking in adolescence: Shared genetic, environmental and psychopathological factors, Journal of Neutral Transmission 114(8): 1097-104.

Linnet, K. M., Dalsgaard, S., Obel, C., et al. (2003), Maternal lifestyle factors in pregnancy risk of attention deficit hyperactivity disorder and associated behaviors: Review of the current evidence, American Journal of Psychiatry, 160: 1028-1040.

Lundberg, S., S. McLanahan and E. Rose (2007), Child Gender and Father Involvement in Fragile Families, Demography, 44: 79-92.

Mauldon, J. (1992), Children's risk of experiencing divorce and remarriage: Do disabled children destabilize marriages. Population studies 46(2): 349-362. 
Mick, E., Biederman, J., Faraone, S. V., and Kleinman, S. (2002a), Case-control study of attention deficit hyperactivity disorder and maternal smoking, alcohol use and drug use during pregnancy, American Journal of Child and Adolescent Psychiatry 41(4): 378-385.

Mick, E., Biederman, J., Prince, J., Fischer, M. J., and Faraone, S. V. (2002b), Impact of low birth weight on attention-deficit/hyperactivity disorder, Journal of developmental and behavioral pediatrics 23(1): 16-22.

Munk-Jørgensen, P. and P. B. Mortensen (1997), The Danish Psychiatric Central Register, Danish Medical Bulletin 44, 82-84.

MTA Cooperative Group (1999), A 14-month randomized clinical trial of treatment strategies for attention-deficit/hyperactivity disorder, The MTA Cooperative Group. Multimodal Treatment Study of Children with ADHD, Arch Gen Psychiatry 56(12): 1073-86.

National Institute for Health and Clinical Excellence (NICE) (2006), Methylphenidate, atomoxetine and dexamfetamine for attention deficit hyperactivity disorder (ADHD) in children and adolescents, Review of Technology Appraisal 13.

Noonan, K., Reichman, N. E., and Corman, H. (2005), New fathers' labor supply: Does child health matter? Social Science Quarterly, 86(1): 1399-1417.

Pliszka, S. R., Crismon, M. L., Hughes, C.W. et al. (2006), The Texas Children's Medication Algorithm Project: revision of the algorithm for pharmacotherapy of attentiondeficit/hyperactivity disorder, Journal of the American Academy of Child and Adolescent Psychiatry,45(6): 642-57.

Powers, E. T. (2003), Children's health and maternal work activity: Static and dynamic estimates under alternative disability definitions, Journal of Human Resources 38(3): 522-36.

Reichman, N.E., Corman, H., Noonan, K. (2008), Impact of child disability on the family, Maternal and Child Health Journal 12(6): 679-683. 
Reichman, N. E., Corman, H., and Noonan, K. (2004), Effects of child health on parents' relationship status, Demography 41(3): 569-584.

Spencer, T., Biederman, J., Wilens, T., Harding, M., O’Donnell D., Griffin, S. (1996), Pharmacotherapy of attention-deficit hyperactivity disorder across the life cycle, Journal of the American Academy of Child and Adolescent Psychiatry, 35(4): 409-32.

Thunstrom, M. (2002), Severe sleep problems in infancy associated with subsequent development of attention-deficit/hyperactivity disorder at 5.5 years of age, Acta Paediatrica, 91(5): 584-592.

Zimmer, D. (2007), Child health and maternal work activity: The role of unobserved heterogeneity, Eastern Economic Journal, 33(1).

Wehmeier, P. M., Schacht, A., and Barkley, R. A. (2010), Social and emotional impairment in children and adolescents with ADHD and the impact on quality of life, Journal of Adolescent Health, 46(3): 209-217.

World Health Organization (1992), The ICD-10 Classification of Mental and Behavioural Disorders: Clinical descriptions and diagnostic guidelines. Geneva, Switzerland: World Health Organization.

Wymbs, B. T., W. E. Pelham et al. (2008), "Rate and predictors of divorce among parents of Youth with ADHD.” Journal of Consulting and Clinical Psychology 76(5): 735-744. 


\section{Appendix $\mathbf{A}^{17}$}

\section{Complications at birth}

- DO60: Preterm labour

- DO61: Failed induction of labour

- DO62: Abnormalities of forces of labour

- DO63: Long labour

- DO64: Obstructed labour due to malposition and malpresentation of fetus

- DO65: Obstructed labour due to maternal pelvic abnormality

- DO66: Other obstructed labour

- DO67: Labour and delivery complicated by intrapartum haemorrhage, not elsewhere classified

- DO68: Labour and delivery complicated by fetal stress [distress]

- DO69: Labour and delivery complicated by umbilical cord complications

- DO75: Other complications of labour and delivery, not classified elsewhere

\section{Complications in the perinatal period}

- DP00-04: Fetus and newborn affected by maternal factors and by complications of pregnancy, labour and delivery

- DP05: Slow fetal growth and fetal malnutrition

- DP10: Intracranial laceration and haemorrhage due to birth injury

- DP11: Other birth injuries to central nervous system

- DP20-29: Respiratory and cardiovascular disorders specific to the perinatal period

- DP35-39: Infections specific to the perinatal period

\footnotetext{
${ }^{17}$ International Statistical Classification of Diseases and Related Health Problems 10th Revision Version for 2007: http://apps.who.int/classifications/apps/icd/icd10online/
} 


\section{Appendix B}

\section{TABLE B1}

\section{FULL SET OF COEFFICIENTS}

The Effect of Having a Child with ADHD on Parents' Outcomes 10 Years after Child Birth, 2,457 treated and 169,842

\begin{tabular}{|c|c|c|c|c|c|c|c|c|}
\hline \multirow[t]{5}{*}{ nontreated } & \multicolumn{2}{|c|}{ (1) } & \multicolumn{2}{|c|}{ (2) } & \multicolumn{2}{|c|}{ (3) } & \multicolumn{2}{|c|}{ (4) } \\
\hline & \multicolumn{2}{|c|}{ Relationship Dissolution } & \multirow{2}{*}{\multicolumn{2}{|c|}{$\begin{array}{c}\text { Intensive Labor Supply } \\
\text { Mother }\end{array}$}} & \multicolumn{2}{|c|}{ Intensive Labor Supply } & \multicolumn{2}{|c|}{ Extensive Labor Supply } \\
\hline & \multirow{2}{*}{\multicolumn{2}{|c|}{ Probit }} & & & \multirow{2}{*}{\multicolumn{2}{|c|}{$\begin{array}{c}\text { Father } \\
\text { OLS } \\
\end{array}$}} & \multirow{2}{*}{\multicolumn{2}{|c|}{$\begin{array}{c}\text { Mother } \\
\text { Probit }\end{array}$}} \\
\hline & & & \multicolumn{2}{|c|}{ OLS } & & & & \\
\hline & Marg.eff. & S.e. & Coeff. & S.e. & Coeff. & S.e. & Marg.eff. & S.e. \\
\hline \multicolumn{9}{|l|}{ Treatment: } \\
\hline ADHD & $\mathbf{0 , 1 3 0}$ & 0,010 & $-7,624$ & 2,029 & $-5,120$ & 1,936 & $-0,017$ & 0,007 \\
\hline \multicolumn{9}{|l|}{ Child: } \\
\hline Birth weight less than 2,500 grams $(0 / 1)$ & $-0,017$ & 0,011 & $-1,275$ & 2,283 & 1,301 & 2,201 & $-0,004$ & 0,008 \\
\hline Gestation length (weeks) & $-0,001$ & 0,001 & 0,420 & 0,127 & 0,201 & 0,126 & 0,001 & 0,000 \\
\hline Gestation length (weeks) missing (0/1) & $-0,032$ & 0,026 & 16,116 & 5,431 & 7,841 & 5,429 & 0,045 & 0,014 \\
\hline Complications at birth $(0 / 1)$ & $-0,007$ & 0,003 & $-0,607$ & 0,621 & 0,931 & 0,608 & $-0,003$ & 0,002 \\
\hline Complications in the perinatal period $(0 / 1)$ & 0,009 & 0,005 & $-2,517$ & 1,049 & $-0,720$ & 1,029 & $-0,007$ & 0,004 \\
\hline 5-minute APGAR score & 0,001 & 0,001 & $-0,214$ & 0,239 & $-0,003$ & 0,243 & $-0,001$ & 0,001 \\
\hline 5-minute APGAR score missing $(0 / 1)$ & 0,015 & 0,018 & 0,066 & 3,290 & 2,561 & 3,302 & $-0,005$ & 0,013 \\
\hline $\operatorname{Boy}(0 / 1)$ & $-0,005$ & 0,002 & 0,395 & 0,435 & $-0,377$ & 0,430 & 0,000 & 0,002 \\
\hline \multicolumn{9}{|l|}{ Mother: } \\
\hline Age at child birth & $-0,009$ & 0,000 & 0,119 & 0,085 & 0,652 & 0,083 & $-0,001$ & 0,000 \\
\hline High school (0/1) ${ }^{a}$ & $-0,070$ & 0,003 & 38,053 & 0,854 & 9,258 & 0,826 & 0,078 & 0,002 \\
\hline Vocational education (0/1) ${ }^{\mathrm{a}}$ & $-0,067$ & 0,003 & 26,874 & 0,677 & 6,423 & 0,637 & 0,054 & 0,002 \\
\hline Short further education $(0 / 1)^{a}$ & $-0,089$ & 0,005 & 33,328 & 1,198 & 6,377 & 1,195 & 0,063 & 0,003 \\
\hline Medium further education $(0 / 1)^{a}$ & $-0,117$ & 0,003 & 48,815 & 0,787 & 10,098 & 0,805 & 0,107 & 0,002 \\
\hline Long further education $(0 / 1)^{a}$ & $-0,093$ & 0,005 & 49,334 & 1,135 & 9,794 & 1,103 & 0,084 & 0,002 \\
\hline Education missing $(0 / 1)$ & $-0,072$ & 0,012 & 5,699 & 3,441 & 3,925 & 3,342 & 0,019 & 0,008 \\
\hline Duration of unemployment (weeks) & 0,001 & 0,000 & $-0,074$ & 0,027 & $-0,031$ & 0,024 & 0,000 & 0,000 \\
\hline Gross income (dkk100,000) & 0,006 & 0,002 & 0,346 & 0,451 & $-0,518$ & 0,386 & $-0,008$ & 0,001 \\
\hline No. of working weeks in a year & $-0,001$ & 0,000 & 1,037 & 0,021 & 0,149 & 0,019 & 0,003 & 0,000 \\
\hline Psychiatric diagnosis $(0 / 1)$ & 0,104 & 0,007 & $-29,502$ & 1,556 & $-4,505$ & 1,427 & $-0,096$ & 0,006 \\
\hline Heart disease $(0 / 1)$ & 0,007 & 0,008 & $-3,636$ & 1,635 & $-1,040$ & 1,573 & $-0,015$ & 0,006 \\
\hline Respiratory disease $(0 / 1)$ & $\mathbf{0 , 0 3 5}$ & 0,004 & $-3,309$ & 0,723 & 0,524 & 0,692 & $-0,013$ & 0,003 \\
\hline Smoker $(0 / 1)$ & 0,090 & 0,009 & $-1,774$ & 1,667 & $-2,026$ & 1,619 & $-0,012$ & 0,006 \\
\hline Smoker missing $(0 / 1)$ & 0,006 & 0,005 & 0,222 & 0,966 & $-0,246$ & 0,955 & $-0,003$ & 0,004 \\
\hline Smoker*Psychiatric diagnosis (parents) $(0 / 1)$ & $-0,020$ & 0,019 & $-2,225$ & 4,785 & 12,161 & 4,468 & 0,001 & 0,013 \\
\hline Married before $(0 / 1)$ & 0,058 & 0,008 & $-1,778$ & 1,501 & $-0,351$ & 1,495 & $-0,006$ & 0,005 \\
\hline \multicolumn{9}{|l|}{ Father: } \\
\hline Age at child birth & 0,000 & 0,000 & 0,121 & 0,065 & $-1,519$ & 0,067 & 0,000 & 0,000 \\
\hline High school $(0 / 1)^{a}$ & $-0,062$ & 0,004 & 10,551 & 0,961 & 28,031 & 0,962 & $\mathbf{0 , 0 3 1}$ & 0,003 \\
\hline Vocational education $(0 / 1)^{a}$ & $-0,056$ & 0,003 & 8,811 & 0,609 & 12,300 & 0,609 & $\mathbf{0 , 0 2 3}$ & 0,002 \\
\hline Short further education $(0 / 1)^{a}$ & $-0,096$ & 0,004 & 3,080 & 0,992 & 7,060 & 1,053 & 0,013 & 0,003 \\
\hline Medium further education $(0 / 1)^{a}$ & $-0,085$ & 0,004 & 9,773 & 0,903 & 38,239 & 0,835 & $\mathbf{0 , 0 3 2}$ & 0,003 \\
\hline Long further education $(0 / 1)^{a}$ & $-0,101$ & 0,004 & 4,351 & 1,022 & 34,102 & 0,991 & $\mathbf{0 , 0 2 0}$ & 0,003 \\
\hline Education missing $(0 / 1)$ & $-0,002$ & 0,010 & $-6,812$ & 2,336 & 0,619 & 2,450 & $-0,019$ & 0,007 \\
\hline
\end{tabular}

Note : Gross income, no. of working weeks in a year, and duration of unemployment are measured in the year before the first childbirth.

Gross income is in 2004 prices.

Reference category: a. Primary school, b. Gross income below 170,000dkk., c. Copenhagen and d. 1997.

Bold figures denote significance at the $5 \%$ level.

Italic figures denote significance at the $10 \%$ level. 
TABLE B1 (Continued)

FULL SET OF COEFFICIENTS

The Effect of Having a Child with ADHD on Parents' Outcomes 10 Years after Child Birth, 2,457 treated and 169,842

\begin{tabular}{|c|c|c|c|c|c|c|c|c|}
\hline \multirow[t]{2}{*}{ nontreated } & \multicolumn{2}{|c|}{$(1)$} & \multicolumn{2}{|c|}{$(2)$} & \multicolumn{2}{|c|}{ (3) } & \multicolumn{2}{|c|}{ (4) } \\
\hline & \multicolumn{2}{|c|}{ Relationship Dissolution } & \multicolumn{2}{|c|}{$\begin{array}{c}\text { Intensive Labor Supply } \\
\text { Mother }\end{array}$} & $\begin{array}{r}\text { Intensive } \\
\mathrm{Fa} \\
\mathrm{C}\end{array}$ & $\begin{array}{l}\text { bor Supply } \\
\text { er } \\
\end{array}$ & $\begin{array}{r}\text { Extensive } \\
\mathrm{M} \\
\mathrm{P} \\
\end{array}$ & oor Supply \\
\hline Duration of unemployment (weeks) & 0,002 & 0,000 & $-\mathbf{0 , 0 5 8}$ & 0,028 & 0,286 & 0,031 & 0,000 & 0,000 \\
\hline Gross income between $170,000-200,000 \mathrm{dkk}(0 / 1)$ & $-0,015$ & 0,005 & $-2,592$ & 1,128 & $-11,734$ & 1,198 & $-0,005$ & 0,004 \\
\hline Gross income between 200,000 - 230,000dkk (0/1̊) & $-\mathbf{0 , 0 3 7}$ & 0,004 & 1,000 & 1,038 & $-13,050$ & 1,092 & 0,002 & 0,003 \\
\hline Gross income between $230,000-260,000 \mathrm{dkk}\left(0 / 1^{b}\right)$ & $-\mathbf{0 , 0 5 3}$ & 0,004 & 3,179 & 1,004 & $-11,475$ & 1,057 & $\mathbf{0 , 0 1 0}$ & 0,003 \\
\hline Gross income between 260,000 - 290,000dkk (0/1') & $-0,051$ & 0,005 & 2,703 & 1,028 & $-11,340$ & 1,079 & 0,005 & 0,003 \\
\hline Gross income between $290,000 \mathrm{dkk}-320,000 \mathrm{dkk}^{\mathrm{b}}(0 / 1$ & $1 \ngtr 0,052$ & 0,005 & 1,972 & 1,076 & $-12,346$ & 1,127 & 0,007 & 0,004 \\
\hline Gross income between 320,000 - 350,000dkk (0/1) & $-0,051$ & 0,005 & $-0,274$ & 1,159 & $-15,123$ & 1,205 & 0,005 & 0,004 \\
\hline Gross income above $350,000 \mathrm{dkk}(0 / 1)$ & $-0,050$ & 0,005 & $-10,655$ & 1,028 & $-24,591$ & 1,103 & $-0,028$ & 0,004 \\
\hline No. of working weeks in a year & 0,000 & 0,000 & 0,309 & 0,018 & 1,741 & 0,021 & 0,001 & 0,000 \\
\hline Psychiatric diagnosis $(0 / 1)$ & 0,099 & 0,007 & $-5,603$ & 1,412 & $-24,869$ & 1,502 & $-0,010$ & 0,005 \\
\hline Heart disease $(0 / 1)$ & 0,014 & 0,007 & $-0,401$ & 1,399 & $-6,120$ & 1,456 & $-0,004$ & 0,005 \\
\hline Respiratory disease $(0 / 1)$ & $\mathbf{0 , 0 3 1}$ & 0,004 & 0,194 & 0,775 & $-3,864$ & 0,776 & $-0,001$ & 0,003 \\
\hline Married before $(0 / 1)$ & 0,003 & 0,006 & $-0,397$ & 1,167 & 2,964 & 1,215 & $-0,005$ & 0,004 \\
\hline Child (children) with another mother (mothers) $(0 / 1)$ & $\mathbf{0 , 0 8 8}$ & 0,005 & 1,173 & 0,991 & $-8,432$ & 1,039 & 0,003 & 0,003 \\
\hline \multicolumn{9}{|l|}{ Father and mother: } \\
\hline Married at child birth $(0 / 1)$ & $-0,056$ & 0,002 & $-6,368$ & 0,460 & $-3,519$ & 0,457 & $-0,021$ & 0,002 \\
\hline Years together when child born & $-0,016$ & 0,001 & 1,776 & 0,090 & 1,408 & 0,090 & 0,005 & 0,000 \\
\hline Immigrants (one or both parents) $(0 / 1)$ & $-0,015$ & 0,005 & $-21,886$ & 1,116 & $-24,153$ & 1,151 & $-0,057$ & 0,004 \\
\hline Northern Jutland $(0 / 1)$ & $-0,089$ & 0,004 & $-7,105$ & 0,843 & $-1,353$ & 0,825 & $-0,012$ & 0,003 \\
\hline Zealand $(0 / 1)$ & $-0,033$ & 0,003 & $-2,045$ & 0,713 & $-2,057$ & 0,714 & $-0,005$ & 0,003 \\
\hline Southern Jutland $(0 / f)$ & $-0,074$ & 0,003 & $-4,786$ & 0,612 & $-0,161$ & 0,606 & $-0,009$ & 0,002 \\
\hline Central Jutland $(0 / 1)$ & $-0,086$ & 0,003 & $-3,295$ & 0,624 & 0,628 & 0,618 & $-0,005$ & 0,002 \\
\hline \multicolumn{9}{|l|}{ Year-dummies: } \\
\hline $1990^{\mathrm{d}}$ & $-0,021$ & 0,007 & $-2,571$ & 1,322 & $-2,256$ & 1,309 & $-0,001$ & 0,005 \\
\hline $1991^{\mathrm{d}}$ & $-0,019$ & 0,005 & $-0,208$ & 0,984 & $-0,007$ & 0,971 & 0,001 & 0,004 \\
\hline $1992^{\mathrm{d}}$ & $-0,013$ & 0,005 & $-2,304$ & 0,992 & $-6,459$ & 0,995 & $-0,015$ & 0,004 \\
\hline $1993^{\mathrm{d}}$ & $-0,010$ & 0,005 & $-2,592$ & 0,994 & $-3,054$ & 0,979 & $-0,016$ & 0,004 \\
\hline $1994^{\mathrm{d}}$ & $-0,002$ & 0,005 & $-3,146$ & 0,924 & $-3,022$ & 0,907 & $-0,015$ & 0,004 \\
\hline $1995^{\mathrm{d}}$ & 0,008 & 0,005 & $-3,763$ & 0,917 & $-3,228$ & 0,903 & $-0,011$ & 0,004 \\
\hline $1996^{\mathrm{d}}$ & 0,016 & 0,005 & $-1,289$ & 0,909 & $-1,559$ & 0,898 & 0,000 & 0,004 \\
\hline
\end{tabular}

Note: Gross income, no. of working weeks in a year, and duration of unemployment are measured in the year before the first childbirth.

Gross income is in 2004 prices.

Reference category: a. Primary school, b. Gross income below 170,000dkk., c. Copenhagen and d. 1997.

Bold figures denote significance at the $5 \%$ level.

Italic figures denote significance at the $10 \%$ level. 
FIGURE B1

PARENTS' OUTCOMES BEFORE AND AFTER CHILDREN'S ADHD

DIAGNOSIS

\section{Civil Status}

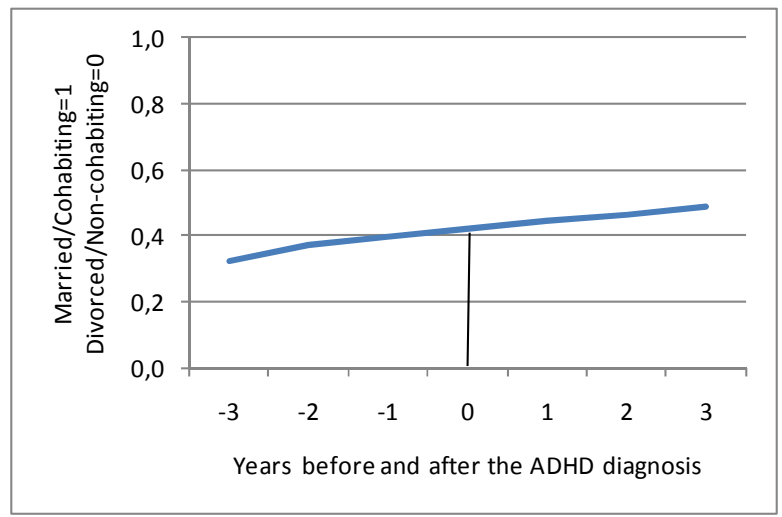

Mothers' Intensive Labour Supply

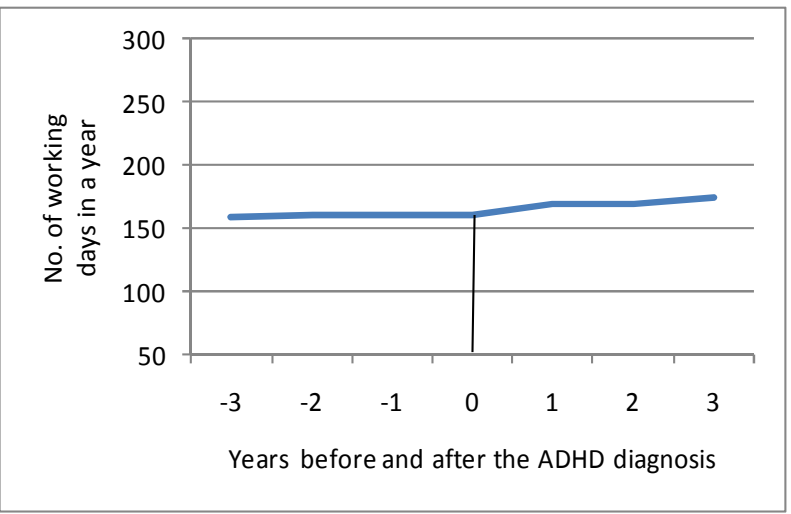

Note: No. of observations 1,003 